\title{
Optimized cool roofs: integrating albedo and thermal emittance with R-Value
}

\author{
A.R. Gentle, J.L.C. Aguilar and G.B. Smith \\ School of Physics and Advanced Materials, University of Technology, Sydney, PO Box \\ 123, Broadway NSW 2007 Australia \\ Email g.smith@uts.edu.au
}

\begin{abstract}
For cool roofs the combined effect of the three parameters that define heat gain and loss from a roof, namely solar albedo $\alpha$, thermal emittance $E$, and sub-roof R-value must be considered. An accurate contribution of night sky cooling, and hence humidity and total down-welling atmospheric radiation is needed. A systematic analysis of the contribution of a roof to average cooling load per day and to peak load reductions is presented for a temperate climate zone over six cooling months using an hour-by-hour analysis. Eighteen 3-parameter sets ( $\alpha, E, R)$ demonstrate the over-riding importance of a high $\alpha$, while sensitivity to R-value and E drops away as albedo rises. Up-front cost per unit reductions in peak demand or average energy use per day always rises strongly as $\mathrm{R}$ rises unless albedo is low. A moderate $\mathrm{R} \sim$ 1.63 is superior to high $\mathrm{R}$ unless a roof is dark, or winter heating demand is high. We indicate briefly why the roof is typically not at present a dominant influence on average winter heating needs in most temperate zones, enhancing the benefits of cool roofs.
\end{abstract}

Key words : cool roof, albedo, emittance, R-value, cooling load, peak demand, cost benefits

\section{Introduction}

"Cool roofs" have been of increasing interest recently [1, 2] because they can increase summer interior average thermal comfort levels significantly under freerunning (i.e non-air conditioned) conditions, or can reduce average power needed 
in conditioned spaces. Both are of interest but have different measures. Performance under free-running is determined by the number of discomfort days as measured by internal zone temperatures $\mathrm{T}_{\text {zone }}$ exceeding a desired maximum. Total power consumption for interior cooling needed to avoid exceeding a pre-set maximum $\mathrm{T}_{\text {zone }}$ (set at $25^{\circ} \mathrm{C}$ in this study) provides a conditioned performance measure. Energy ratings based on either measure can differ significantly for the same building design though they tend to converge when power needs are very low, that is in the highest rating buildings [3]. In the case of conditioned spaces roofs also have a strong influence on peak summer power demand, which is of growing concern to utilities. Roof related heat gains peak when solar flux $\Phi_{S}(t)$ is highest and cooling power demands usually peak an hour or two later, when electricity is most expensive and blackouts may be a high risk. In this study we will consider average daily and monthly cooling loads for the whole cooling season, as well as peak summer loads.

"Cool roofs" are commonly defined as having a high solar reflectance or albedo $\alpha$, and hence the focus has been on heat gains in the daytime. While this is a key feature overall performance is also dictated by other material and design factors, and what happens at night in terms of additional passive cooling. The other material parameters of main interest are the roof's external emittance $\mathrm{E}$ and the R-value (or $\mathrm{U}$-value $=1 / \mathrm{R}$ ) of any insulation immediately under the roof. Roof and building thermal mass is relevant but is fixed in this study. Internal loads are also neglected so we can focus on heat flow impacts of the material and meteorological influences, including the sun, the atmosphere, and air flow or wind. Ceilings if present between the roof and the occupied space, and insulation on ceilings, as used in many in homes can be considered separately but for simplicity in the core message in this report results are confined to the influence of the roof including sub-roof insulation, and roof surfaces as one unit. From an initial cost perspective it is desirable to achieve the maximum energy savings (or minimum discomfort days) per dollar 
invested in the overall roof structure, that is cost benefits or return-on-investment. Payback period from energy savings could also be included for conditioned spaces.

Traditionally building codes have focused on more roof insulation i.e. increased Rvalues, but more recently the extent of energy saving, comfort and environmental benefits of a high roof albedo in warm climates have come into prominence $[1,2,4$ 7]. The impact of emittance and hence night sky cooling, though treated reasonably well from a physics/environmental perspective in some computer codes is often modeled poorly and has been widely underrated in its impact. Raising roof R-values and hence cost of insulation reduces daytime heat gains, but at the expense of nighttime heat losses. High $\mathrm{R}$ in combination with thermal mass can trap daytime heat gains over the following night unless much cool air ventilation is available and utilised. Making the most of all available night cooling opportunities is especially important in buildings with significant internal heat gains. A systematic study of how $\alpha$ and $E$ combine with a range of R-values embodies useful lessons and insights for new designs and for retrofitting. Changing roof coatings or modifying R-values, can be part of regular maintenance. They are relatively inexpensive and come with important little recognized bonus benefits some of which are outlined briefly in the next section. Other factors of importance include thermal mass, roof slope, roof-towall area ratio, orientation, the time dependence and magnitude of internal loads, and air exchange rates. All are fixed in this report so we can focus on roof material properties.

Then a systematic study of the way the three parameters $(\alpha, E, R)$ in combination dictate the overall cooling demand and peak load contributions of a roof, along with the initial cost-benefits of varying $R$ for different $(\alpha, E)$ combinations provides important guidelines on how to achieve maximum savings per dollar invested in buildings where cooling demand is needed either over just six months, or most of a year. One common misconception is that R-values should be as high as possible. We will show clearly that is not the case though R does need to rise for "non-cool roofs". 
We confine results in this report to cooling demand over six dominant cooling months in a temperate zone. The central insights that follow can be readily extended to even warmer climates where cooling demand extends over nearly a full year according to limited results we have to date. These are interesting in their own right, especially in terms of night-time effects even in hot-humid zones, and will be reported separately. In temperate climates like that in most Australian cities, total electric power or gas energy use for winter heating in homes can at present be two to three times higher than summer cooling demand in well established homes. Why is this and does it mean optimally that to maximize year round savings less high roof solar absorptance may be required? Two points are relevant in such climates. First while the roof contribution to cooling demand in summer is very sensitive to changing albedo we find its contribution to winter heating demand varies only slightly with the same changes. For example raising albedo by 0.4 typically reduces total cooling demand by a factor 2 to 3 but only raises heating demand by around $10 \%$ or less. Secondly the roof contributes at most $1 / 4$ to $1 / 3 \mathrm{rd}$ of total heating demand in winter in most established Australian homes. The remainder is primarily due to excessive cold air infiltration, along with the fact that heating is needed more at night when people are home. This is the key finding of a detailed study on the influence of air infiltration rates on cooling and heating demand. While some modern Australian homes designed for energy efficiency have improved air tightness, we are aware of no examples (though they probably exist in our alpine regions where few reside) which employ established cold climate techniques where heat exchangers warm incoming air. In sub-tropical and warmer climates, and in commercial, industrial, retail and institutional buildings with large internal heat loads, cooling needs extend for longer periods and cool roof design is even more important. Two facts are clear already in temperate zones (i) that the benefits of a bias to cool roofs persist on an annual analysis in most building types (ii) that in homes in temperate zones reductions in air exchange rates in winter, can strongly reduce heating needs and should be an additional high priority to cooler roofs. Coupled with cool roofs large total annual savings will follow. 


\subsection{Bonus benefits of optimized cool roofs}

Cool roofs can have substantial additional benefits beyond the direct thermal impacts within a single building that we examine in detail this study. These bonuses arise even when the direct energy savings from changes to the roof parameters are moderate fractions of total annual energy use in that building. Peak demand reductions are one bonus already mentioned. Meeting peak demand on a handful of days is demanding on capital investment in grid capacity, power sources and chiller capacity. It involves inefficient energy use in stand-by power stations, which have to run at low output in readiness. Current high peak demand growth in summer is of growing concern to utilities, homes and businesses. If widely implemented cool roofs could lower peak summer demand significantly in various ways. Much of the recent growth in air conditioning use in temperate countries like Australia is attributable to avoiding overheating discomfort on a handful of worst days each year so its amelioration with better building design, including ideally variable ventilation, can mean that the alternative, comfortable free-running, is often quite viable. Then in most homes air conditioners would be unnecessary.

Another bonus from high $\alpha$, high E roofs in addition to cutting peak demand and overall energy use is worth consideration, despite not yet being quantified. It involves improvements in microclimates around each building and probably in the local urban or industrial precincts if most buildings therein have cool roofs. This opens up a means of amelioration of the urban heat island problem [4, 8-11], which adds significantly to cooling demand in various ways, especially via air exchange. First raising average local albedo reduces thermal storage in buildings and provides cooler air close to the building. Secondly sub-ambient roofing at night resulting from high E leads to cool air just above a roof which can flow by natural convection off the roof to cool walls and surrounds. High $\alpha$ roofs also have much cooler air just above them in the daytime which can raise Coefficient-of-Performance (COP) in conditioners. More free-running comfortable buildings means less pumping of heat 
from interiors into the outside, which adds to the urban heat island (UHI) problem. Cooler precincts mean lower cooling demand in all neighbouring buildings.

Finally at the very large scale direct global cooling can result if a high enough percentage of the world's roofs are made "cool" [1,5]. Other global impacts associated with reduced need for compressor driven cooling [12] include lower emission of two greenhouse gases $\mathrm{CO}_{2}$, and refrigerant gases via leakage. It is interesting in this context and worthy of detailed future study to compare to cool roofs the cost and impact on peak demand, the UHI and the local and global environment of the following growing approaches for air conditioning aimed at lower $\mathrm{CO}_{2}$ emissions (i) cooling compressors driven by photovoltaic generated solar power (ii) solar thermal driven absorption cycle chillers (iii) bi-generation and trigeneration plants using gas driven local power and absorption cycle chillers. Solar output also peaks in performance an hour or two before peak demand but the cost per each MW of peak demand reduction is much lower for a cool roof than for solar PV power systems [5]. Normal inefficiencies in roof-mounted solar systems both PV and thermal, add heat to the UHI. Local gas fired power plants add heat and moisture to a precinct, while absorption chillers have low COP's near 1.0 and hence pump a lot more heat nearby than typical modern electric compressors. This may include nearly all the solar energy falling on a roof covered with efficient solar thermal collectors if they supply heat to the chiller. This could be up to 8 to 9 times the precinct or UHI heat load addition from a cool roof. PV (ignoring cost) is likely to be the more attractive option of these three, apart from a cool roof. A combination of cool roof and PV is also of interest. PV systems suitably mounted onto otherwise cool roofs should perform with higher efficiency due to cooler air near them as shown in another cell cooling approach recently [13]. Less cells will be needed anyway if cooling demand is reduced.

\section{Material properties and roof heat flows}


High E requires high infra-red absorptance across the Planck spectrum of black body wavelengths for near ambient temperatures. Combining the ideal high solar reflectance and high IR absorptance in a single surface, requires a large spectral switch near $2.5 \mu \mathrm{m}$ and is quite practical with select paints and some vacuum and chemically coated systems [12]. Such combinations are spectrally selective as they have exactly opposite reflectance character over the solar and Planck wavelength zones [12]. Other paint and coating options with slightly lower $\alpha$, but still with high E, are available if color is desirable $[14,15]$. It is also of practical interest for a roof to note that a water layer or droplets on a high $\alpha$, high $\mathrm{E}$ roof, either deliberately for extra cooling, or from cooling below the dew point, maintains high E. Thus even if water condenses radiative cooling at night can continue and achieve even lower temperatures than the dew point.

The key components of heat flows via a roof between interiors of a building to and from the local environment are illustrated schematically in figure 1. To solve for heat flows and the two temperatures to which they are easily linked, namely $\mathrm{T}_{\text {roof }}$ at the outer surface and $\mathrm{T}_{\text {zone }}$ in the interior below the roof material plus any insulation, each flux in figure 1 must be first defined. The following weather and materials data are needed (i) elements of local climate at each sampling time $t$; solar flux $\Phi_{S}$, ambient temperature $T_{A}$, humidity and its impact on effective sky temperature $\mathrm{T}_{\text {sky }}$ or if measured total down-welling thermal radiation from the atmosphere $\Phi_{\mathrm{A}}$, wind speed $\mathrm{v}_{\mathrm{W}}$ (ii) the spectral properties of the outer roof surfaces; albedo $\alpha$ and thermal emittance $\mathrm{E}$ (iii) the thermal resistance to heat flow or R-value between roof surface and interiors. With this data the direction and quantity of heat flow, plus $T_{\text {roof, }}$ and $T_{\text {zone }}$ at any time $t$ can be found using equation (1) which is a mathematical representation of figure 1 under steady state conditions.

$$
(1-\alpha) \Phi_{S}(t)+E \Phi_{A}\left(t, T_{A}, T_{\text {sky }}\right)-E \sigma T_{\text {roof }}^{4}-\Phi_{C}\left(T_{\text {roof }}, T_{A}, v_{w}\right)=\frac{1}{R}\left[T_{\text {roof }}-T_{\text {zone }}\right]
$$


A surface heat transfer coefficient on the exterior is not needed in this model as all external heat flows are handled explicitly in (1). At the inner surface our detailed models following include surface influence but it is very small relative to the insulation R so (1) is a good approximation. Alternately (1) applies with this term included in R. Any inwards flow is subsequently part stored in internal air and building mass, and part exhausted using an air conditioner. $\mathrm{T}_{\text {zone }}$ is the room or zone temperature, which has a fixed maximum for this exercise in which we wish to isolate roof contributions to heating and cooling loads, without complications from other heat sources including flows through walls and floors. The latter two are thus well insulated and sealed to avoid additional heat flows. For free-running $\mathrm{T}_{\text {zone }}$ is fully variable and to be determined. $\Phi_{\mathrm{C}}$ is the convective exchange with the local ambient and can be negative at night if $\mathrm{T}_{\text {roof }}<\mathrm{T}_{\mathrm{A}}$ when convective heat flows into the roof. For simplicity we have also omitted moisture related latent heat contributions to heat gain and loss. This systematic, slightly simplified analysis of the impact of the three materials parameters in equation (1) provides clear and important insights into the most cost effective approaches to energy efficient roof design and to the magnitudes of benefits that will arise from wide-scale use, including the extent of peak load reductions.

Equation (1) involves energy absorbed by a roof from the environment, energy reemitted and energy transmitted. Reflected intensity $\Phi_{\mathrm{R}}$ is also worth consideration and involves reflection of solar and atmospheric thermal radiation as in equation (2).

$$
\Phi_{R}=\alpha \Phi_{S}+(1-E) \Phi_{A}
$$

For modeling and discussion purposes it is worth noting that $\Phi_{\mathrm{A}}$ data is available in three common alternative formats depending on the source of weather data. It can come directly as total down-welling radiation, or can be defined as in equation (3) in terms of either an effective sky temperature $\mathrm{T}_{\text {sky }}$ for a uniform hemispherical "sky" 
or the detailed spectral emittance of the atmosphere. The latter has been simplified in equation (3) using an effective atmospheric emittance $E_{A}$, though for accuracy full spectral and solid angle integrals are needed $[12,16]$.

$$
\Phi_{A}=\sigma T_{s k y}^{4}=E_{A} \sigma T_{A}^{4}
$$

$\sigma$ is the Stefan Boltzmann constant. Both $\mathrm{E}_{\mathrm{A}}$ and $\mathrm{T}_{\text {sky }}$ depend strongly on humidity. The real atmosphere is not a uniform hemispherical black body radiator though the definition above with $\mathrm{T}_{\text {sky }}$ uses that equivalence while the second definition also has homogenised the incoming radiation directionally. If a roof does not see this full hemisphere more accurate analysis with directional integrals is needed since much more radiation comes in at high angles to the zenith so more net radiation goes out at angles near vertical. Consequences include that a horizontal roof surface will cool more than one with a tilt. It is also worth considering in future using roof profile designs as well as coatings to enhance cooling. Ideally however the raised sections might need low $E$ values and the flat sections high $E$ to achieve enhanced cooling as has already been demonstrated in radiative cooling systems by Trombe [17] and one of the authors [16].

\section{Modeling procedures}

The results reported in the next section were obtained using EnergyPlus [18] in the simple one zone structure shown in figure 2. Detailed fixed building specifications used in all models in this study are listed below. The benefits of doing the bulk of this study in EnergyPlus is that it becomes possible to systematically extend later to explore and compare one at a time, for the same sets of roof parameters, shifts in cooling and heating needs when other factors such as air exchange, various window systems, wall gains, and internal loads are included. Important lessons follow that can be lost in complex one-off analyses. 
We have used Representative Meteorological Year Climate Files (RMY) of weather data for Sydney, Australia [19] which has a temperate climate, with cooling demand in homes largely confined to the period October to the end of March and peaking, often very strongly, in January. The issue of currently observed practical heating demand in similar zones for the remainder of the year requires as stated above introduction of air infiltration rates, for which details are beyond the scope of this report. However as noted above the roof contribution to total heating demand, in direct contrast to cooling demand, is weakly sensitive to albedo changes. Though not insignificant it is a minor fraction of total winter heating demand at present in most homes. Currently air exchange rates dominate by factors of 2 to 4 . We also find small internal loads, which are ubiquitous in today's homes, lead to reductions in heating needs 2 to 3 times their value. Adding these in with intermediate albedo values $\sim 0.6$ and a common $\mathrm{R}=1.63$ means heating and cooling contributions with no air exchange are very similar. For any R-value over a whole year total heat or "cold" that has to be removed is always lowest for the highest albedo in the absence of air exchange. Relative external energy required and associated $\mathrm{CO}_{2}$ emissions depends on the systems used for cooling (COP) and heating, which may utilise gas or electricity. Heating via an energy efficient heat pump is becoming more common.

The R-values used in our results are $0.5,1.63$ and 3.06 in units $\left(\mathrm{m}^{2}-\mathrm{K}\right) /$ Watt. Glass fibre and polystyrene batts with $\mathrm{R}=1.63$ are common in many existing nonresidential roofs in temperate zones and have typical thickness around $50 \mathrm{~mm}$, while $\mathrm{R}=3.06$ represents double this thickness and hence higher cost. Even larger $\mathrm{R}$ is being now demanded or used in some areas. We can show $\mathrm{R}>3.06$ has little benefit, and may even reduce annual energy savings if albedo is high. It always involves a very large drop in cost benefit. For each $\mathrm{R}$ value we will present results for each outside surface parameter set $(\alpha, E)$ with solar absorptance $(1-\alpha)=0.2$, $0.6,0.8$, and emittance $E=0.9,0.6$. Values near these are commonly found with select paints, some treated metal roofs and select ceramic roofs. With each of the 
three R-values, eighteen $(R, \alpha, E)$ combinations arise which we find adequate to quantitatively demonstrate the key systematics. As is common practice residentially no lower temperature limit was set in cooling months so with enhanced passive cooling at night $\mathrm{T}_{\text {zone }}$ can get quite cool at times with substantial benefits next day. Falls in $\mathrm{T}_{\text {roof }}$ and $\mathrm{T}_{\text {zone }}$ linked to night sky cooling are instructive to follow. The two central physical results presented are (i) average heat gain per day over the six cooling months, which dictates cooling load (ii) the peak cooling demand, which occurs in January. Leading up to these we used hourly instant heat gains, daily net total energy flows, and monthly averages. Hourly data included the two temperatures $\mathrm{T}_{\text {roof }}$ and $\mathrm{T}_{\text {zone, }}$ with the latter maximum fixed at $25^{\circ} \mathrm{C}$ for conditioning. Peak cooling demand results arise from data averaged over an hour. This averaging involves pre-set sampling intervals which can be set at various values smaller than an hour. The ideal sampling interval computationally is the largest below which there is minimal shift in this average "peak".

Simple cost benefit is then calculated and plotted using an Australian \$ cost for R based on typical local retail quotes. For simplicity and relevance cost is scaled linearly to thickness. This costing is easily changed for different insulation products and non-linearity with thickness, but is a useful guide. The simple cost benefit as presented is taken as material cost divided by either average energy savings per day or peak load reductions, per $100 \mathrm{~m}^{2}$ of roof area. Other R related costs including installation costs and relative difficulty, plus in some cases need for significant changes to standard insulation support structures, and could be included if desired. Future monetary values of energy savings could also be included as a benefit but the core message is quite clear from the simplified up front cost benefit analysis. Indeed these additions further enhance the most attractive options relative to the other options in the cost benefit results following. Payback times are briefly addressed. 
The test building shown schematically in figure 2 is simple and this design ensures results in this study are not orientation dependent. It has basic dimensions $10 \mathrm{~m} \mathrm{x}$ $10 \mathrm{~m} \times 2.4 \mathrm{~m}$ with one internal zone, no windows and no door. The simulation with Energy Plus used the TARP, DOE-2 algorithm [18], with low internal thermal mass and negligible heat gain or loss via walls and floor. The roof is $1 \mathrm{~mm}$ thick steel so its R-value is negligible relative to the insulation's $\mathrm{R}$ (likewise for $2 \mathrm{~mm}$ steel). Its thermal capacitance $=3900\left(\mathrm{~kJ} / \mathrm{m}^{3} \cdot \mathrm{K}\right)$.

\section{Results and discussion}

Figure 3 shows a collation of average heat load per day per $100 \mathrm{~m}^{2}$ of roof area that has to be removed by the cooling equipment in each month over the 6 month cooling season to keep $\mathrm{T}_{\text {zone }}<25^{\circ} \mathrm{C}$ for a sub-set of five $(\mathrm{R}, \alpha, E)$ parameter sets. Each of the five plots also includes the average daily heat load over the whole 6-month period. Only the highest $\mathrm{E}$ is used in these plots since roof $\mathrm{E}>0.8$ is most common. It also has more plots for $\mathrm{R}=1.63$ as it is also more common at present. The main features are the dominating impact of high albedo (or low $\mathrm{A}_{\text {sol }}$ ) on load. When $\alpha=0.8\left(\mathrm{~A}_{\text {sol }}=0.2\right)$ large changes in R-value have only minor impact. Comparing the three plots with $\mathrm{R}=1.63$ and $\mathrm{E}=0.9$ demonstrates that the largest shifts in load occur when $\alpha$ changes significantly. From $\alpha=0.8$ to 0.2 average cooling load rises in all cases studied from just over $7 \mathrm{kWh}$ thermal per day to almost $20 \mathrm{kWh}$ per day for each $100 \mathrm{~m}^{2}$. Clearly with a dark roof a very high $\mathrm{R}>3.06$ is essential but only a moderate or low R-value is needed if the roof has a high albedo. When cost is considered this disparity gets even worse.

Figures 4 and 5 cover cooling load results for all 18 three-parameter sets. Figure 4 shows the peak load in January as a function of $U$-value $(U=1 / R)$ to highlight its rapid rise as roof conductivity increases at low $\alpha$ (high $A_{\text {sol }}$ ) in contrast with the small rise with $U$ that occurs at high $\alpha$. Figure 5 shows for the same parameter set average cooling load per day over the six month cooling season. Notice also that the 
sensitivity to lowering of the $\mathrm{E}$ value from 0.9 to 0.6 increases as both more solar energy is absorbed by the roof, and as more is conducted inwards. Further comment on $\mathrm{E}$ is here worthwhile. Though high $\mathrm{E}$ appears less important if $\mathrm{A}_{\text {sol }}$ is small at all $\mathrm{R}$ in the simple analysis here further study to be reported in detail later shows that once internal loads increase having a high $\mathrm{E}$ is much more important. Then $\mathrm{R}$ should not get too high to enable night sky cooling to be more effective and to save costs.

It is important to note as in figure 4 that peak load is smaller at $A_{\text {sol }}=0.2$ and $\mathrm{R}=$ 1.63 compared to all $A_{\text {sol }} \geq 0.6$ when $\mathrm{R}=3.06$. This demonstrates that low solar absorptance should be the dominant concern. Importantly from a practical viewpoint peak cooling loads can be reduced in magnitude by factors of 2.5 to 3.5 by lowering $\mathrm{A}_{\text {sol }}$ from current typical values in existing homes for all $\mathrm{R}$. While $\mathrm{R}=3.06$ significantly lowers all peak load magnitudes except for $A_{\text {sol }}=0.2$ this multiplier factor persists. Since most existing dwellings in Sydney have $A_{\text {sol }} \sim 0.5$ or higher average peak load reductions per dwelling of above $1 \mathrm{~kW}$ thermal should be easy to achieve. Similar or even larger cuts should be possible on large commercial buildings such as factories, shopping centres and airport terminals unless they already have low Asol. Many are white though "whiteness" is not a guarantee of high albedo as many white surfaces, especially older products absorb significant near IR solar radiation. On site checks or published spectral data on proposed new paints are thus important. The core result here is that much energy saving is to be gained in temperate (and hotter) zones by lowering $A_{s o l}$ regardless of R-value. It is interesting to compare figures 4 and 5 . They are qualitatively similar in shape, but at each $\mathrm{R}$ changes in $\mathrm{A}_{\text {sol }}$ have a bigger impact on average daily load than on peak load. An average reduction above $10 \mathrm{kWh}$ thermal per day per $100 \mathrm{~m}^{2}$ seems readily achievable in many dwellings even with existing insulation by lowering $A_{\text {sol }}$ by around 0.3 or more. Larger savings are possible if the roof is currently un-insulated or a larger change in $A_{\text {sol }}$ is possible. Over the whole cooling season $10 \mathrm{kWh}$ thermal per day is equivalent to a total load reduction of $1,900 \mathrm{kWh}$ thermal per $100 \mathrm{~m}^{2}$. So with a COP $\sim 3$ savings around 0.7 to $0.8 \mathrm{MWh}$ of electric power per $100 \mathrm{~m}^{2}$ from 
moderate raising of roof albedo could easily be achieved. A typical home with roof area $>100 \mathrm{~m}^{2}$ could thus save in excess of $1 \mathrm{MWh}$ over the cooling season.

Finally consider simple cost benefit in figure 6 for peak load reductions and figure 7 for reductions in daily average load. Here the even greater benefits of low $A_{\text {sol }}$ become abundantly clear since a key issue in achieving large overall gains in energy efficiency or peak reductions is to have measures available which achieve the greatest savings at lowest cost. Figure 6 considers cost per unit of peak load reduction as function of $\mathrm{R}$-value. This simple cost benefit measure is defined as cost (in Australian $\$^{*}$ ) per unit of peak kW thermal load reduction. The reduction is taken here relative to a peak of $10 \mathrm{~kW}$ per $100 \mathrm{~m}^{2}$. This reference is used as a general indicator but savings based on changes to existing values of $(\alpha, E, R)$ instead of (10actual peak load) in $\mathrm{kW}$ could be used for particular buildings. This $10 \mathrm{~kW}$ peak value is considered an undesirable upper limit though many residential roofs currently actually exceed this maximum peak value of $10 \mathrm{~kW}$ thermal per $100 \mathrm{~m}^{2}$. In this case electric cooling would require of order 3 to $4 \mathrm{~kW}$ electric of compressor power per $100 \mathrm{~m}^{2}$ plus additional electric power for fans. Other sources of heat gain add to this "roof peak". This broad ranging measure is based on determining the impacts of various $\mathrm{R}, \alpha$, E combinations with cost determined by the R-value. It has been taken to be linear in insulation thickness and based on typical retail prices for glass fibre batts. The effective cost used per unit $\mathrm{R}$ was Aus* $\$ 168.8$. This will change for different materials and with product variations and is easily scaled. Some nonlinearity with $\mathrm{R}$ and thickness could also be used if needed. Various alternatives could also be considered, such as cost benefit of raising albedo by various amounts during scheduled roof painting maintenance or with a special new paint added for energy savings, with whatever existing R-value is present. Then cost is quite moderate for the paint needed per $100 \mathrm{~m}^{2}$, hence large energy savings arise at low to negligible additional cost if new painting was to occur anyway.

* 1 Aus $\$$ is currently valued at 1.06 US\$ 
Cost benefits in figure 7 were derived in a similar way using savings in average daily thermal load and material costs. For simplicity in neither figure 6 or 7 has labor costs for installation of insulation, or for painting been included, but neither has money saved for less power needed over any set period of years. It is worth noting that in large buildings raising sub-roof $\mathrm{R}$ above current and recent past practice of 1.63 may entail costly changes in sub-roof structural support. All such cost and return on investment modifications are straightforward and nearly all enhance the value and return for raising albedo in preference to raising $R$.

The savings used in figure 7 are per average day referenced to a value of $50 \mathrm{kWh}$ per $100 \mathrm{~m}^{2}$ daily average (which occurs in some dwellings). One could instead use total energy savings over the whole six months or around 180 such days. Dividing the units on the vertical axis by 180 will give a good guide to such cost per $\mathrm{kWh}$ thermal saved over six months per $100 \mathrm{~m}^{2}$ for different R-values. As above for peak loads this is a broad measure for which it is easily seen that cost per electric kWh saved in six months on optimizing, starting from no insulation, will be in general much below the retail cost per electric $\mathrm{kWh}$. This implies a very short payback time, especially if high $A_{\text {sol }}$ is used. Payback time is often used as a measure of return. Considering actual payback time for a specific change in $(\alpha, E, R)$ using for example data as in figure 5 may thus be of more use in retrofitting. Two example savings and payback time queries might be (i) What payback time results with existing $R=1.63$ insulation by lowering roof $A_{\text {sol }}$ by 0.4 (which is often very practical)? (ii) Is it worth doubling thickness of sub-roof insulation at low $\mathrm{A}_{\text {sol }}$ to take $\mathrm{R}=1.63$ to 3.06 ?

\section{Answers :}

(i) The savings from dropping $\mathrm{A}_{\text {sol }}$ by 0.4 per $100 \mathrm{~m}^{2}$ are around $10 \mathrm{Kwh}$ thermal per average day or $1800 \mathrm{kWh}$ for six months. This means around $600 \mathrm{kWh}$ electric, a saving at 20c per kWh of $\$ 120$ each six months. The cost of painting $100 \mathrm{~m}^{2}$ of roof is what has to be paid back. If it is part of routine maintenance net cost will be small or zero, likewise for a new 
building assuming alternate paints have similar costs. If it is done specially for energy savings, payback may take two cooling seasons. If a deliberate lowering of $A_{\text {sol }}$ by 0.7 to 0.8 is carried out, one season payback is possible.

(ii) The savings for raising $\mathrm{R}$ at low $\mathrm{A}_{\text {sol }}$ are a maximum per day of $2 \mathrm{kWh}$ thermal per $100 \mathrm{~m}^{2}$ or over 6 months $360 \mathrm{kWh}$ thermal. Power savings are then under $120 \mathrm{kWh}$ or about $\$ 24$ worth. Cost of raising $\mathrm{R}$ will be above $\$ 240$ per $100 \mathrm{~m}^{2}$. Payback time at more than 10 cooling seasons is not attractive. However it is easy to show using figure 5 that in this scenario of raising $R$, payback time shortens by several years if the roof instead retains a high $\mathrm{A}_{\text {sol }}$.

On high $A_{\text {sol }}$ roofs the importance of high emittance and the overall greater sensitivity to emittance should be noted. Emittance $\mathrm{E}$ is then important in cost benefit terms and lower $\mathrm{E}$ is to be avoided if at all possible. This could be an issue for some treatments of metal roofs. For example we have found such mid-level $\mathrm{A}_{\text {sol }}$ and $\mathrm{E}$ combinations in some aged zinc treated aluminum roof panels.

An obvious question at this point is; does year round heating and cooling performance in a temperate climate, as opposed to the cooling season only analysis just presented, alter the average daily energy demand character seen in figure 5 and the cost benefit curves in figure 7 ? In other words does a year round analysis in such climates, with roof heating added in, modify our conclusions on the best $(\mathrm{R}, \alpha, \mathrm{E})$ combinations for minimizing payback times and maximizing return-on-investment. Intuition might suggest that lowering albedo will raise heating demand, and lowering heating needs will shift the annual bias to higher R-values. In both cases it is magnitudes of such shifts that count. An additional comprehensive quantitative report is needed to fully see what shifts occur and is planned. In summary the key findings are as follows (i) in contrast to the cooling demand the winter heating demand is only quite weakly dependent on roof albedo at all R-values (ii) thus the 
average heating/cooling load per day over a whole year at any chosen $\mathrm{R}$ remains strongly dependent on albedo via cooling demand (ii) changes upon varying $\mathrm{R}$ via its influence on heating demand are more complex with large reductions as $\mathrm{R}$ is initially raised from low values and smaller reductions as R rises above 1.63 (ii) then including heating demand plus cooling demand removes the relative cost benefit indicated in figure 7 for low $\mathrm{R}=0.5$ at albedo 0.8 and makes it inferior to the higher $\mathrm{R}$ values as albedo drops (iv) the magnitude of average year round demand reductions from raising $\mathrm{R}$ above 1.63 do not significantly alter the cost benefit relativities in figure 7 between $R=1.63$ and $R=3.06$. $(\mathrm{v})$ air exchange rates are currently the dominant influence on heating demand in temperate climate homes (but they only moderately influence cooling demand) and need to be reduced (vi) even small internal loads, as in homes, reduce heating demand by multiples of their value, shifting the overall emphasis back towards cooling.

Thus including winter heating does not alter our core conclusion that raising roof albedos should be a high priority goal in temperate and hotter climates. It does however alter some of our "cool roof" findings on optimum R-values by reducing the

attraction of low $\mathrm{R}$ combined with high albedo. However the saving gains and possible losses of summer night cooling from raising $\mathrm{R}$ above 1.63 to 3.06 are still definitely not worth the extra cost. Thus the combination of a high albedo as possible with an intermediate $\mathrm{R}$ value $\sim 1.63$ and high $\mathrm{E}$ are strongly recommended.

\section{Conclusion}

The best performing "cool" roofs for monetary and environmental return on capital investment have their sub-roof R-value tailored to the spectral properties of the roof. Large peak cooling load reductions are possible with a switch to high $\alpha$ (low $A_{\text {sol }}$ ) regardless of $R$-value, but especially at $R \leq 1.63$. As roof albedo and emittance rise to high values lower R- values involve little or no penalty in peak load benefits or overall energy savings from reduced cooling demand. In select cases when 
combined with high enough $\alpha$ lower $\mathrm{R}$ is preferred to high $\mathrm{R}$ from both a thermal performance and cost benefit perspective. Night sky cooling and high E contributes additional cooling. In cost benefit terms $\mathrm{R} \leq 1.63$ plus high $\alpha$ and high $\mathrm{E}$ is clearly the preferred option for cooling while higher R involves a large cost penalty.

The results presented here are focused on roof material properties mainly sub-roof insulation and outer surface spectral responses and are confined to a particular temperate climate zone. This is part of a much wider study including experimental tests with two matching experimental structures. It is an excellent foundation, as then other influences such as air exchange, internal loads, design changes and orientation, plus climate zone changes can be systematically added to assess their relative impacts. These will be covered in future reports. Of most relevance to roof impacts is the issue in temperate zones of winter heating demand. We are often challenged on this issue when it comes to promoting cool roofs. As outlined briefly above roof R-value and albedo in most existing homes are not the major reason heating needs in winter are often much higher than cooling needs in summer for temperate climates. It doesn't however have to be so. The relevant message in this paper's context is that the peak load reductions and savings benefits of cool roofs do not have to be sacrificed to achieve winter-time savings in temperate zones. This means the potential for large summer and winter savings combined in homes with climates like those in Australia, or hotter, is very large.

Acknowledgement An Australian Research Council Discovery grant partially supported this work, along with PhD support for JLCA from CSIRO, in particular Dr Dong Chen.

\section{References}

[1] H. Akbari, S. Menon, A Rosenfeld, Global cooling: increasing world-wide urban albedos to offset $\mathrm{CO}_{2}$, Climatic Change 94 (2009) 275-286. 
[2] K.W. Olsen, G.B. Bonan, J. Feddema, Effects of white roofs on urban temperature in a global climate model, Geophysical Research Letters 37 (2010) L03701 (7pp). [3] M. Kordjamshidi, S. King, Overcoming problems in house energy ratings in temperate climates: A proposed new framework, Energy and Buildings 41 (2009) 125-132.

[4] R. Ennos, Urban cool, Physics World August (2010) 22-25.

[5] I. Edmonds and G.B. Smith, Surface reflectance and conversion efficiency dependence of technologies for mitigating global warming, Renewable Energy, 36 (2011) 1343-1351.

[6] G.B. Smith, A.R. Gentle and I. Edmonds, Urban growth, albedo and global warming, Proc. Solar2010, the $48^{\text {th }}$ AuSES Annual Conference Canberra ACT Australia (refereed-available Online at http://www.auses.org.au/information-portal ). [7] S. Menon, H. Akbari, S. Mahanama, I. Sednev , R. Levenson, Radiative forcing and temperature response to changes in urban albedos and associated $\mathrm{CO}_{2}$ offsets, Environ. Phys. Lett. 5 (2010) 014005 (11pp).

[8] M. Kolokotroni, M. Davies, B. Croxford, S. Bhuiyan, A. Mavrogianni, A validated methodology from prediction of heating and cooling energy demand of buildings within the Urban Heat Island: Case-study of London, Solar Energy 84 (2010) 2246-2255. [9] L. Zhou, R.E. Dickinson, Y. Tian, J. Fang, Q. Li, R.K. Kaufmann, C.J. Tucker, R.B. Myneni, Evidence for significant urbanization effect on climate in China, Proc. National Academy of Sciences 101 (2004) 9540-9544.

[10] M.J. Alcoforado, H. Andrade, Global warming and the urban heat island, ) 249-262 in "Urban Ecology” (Marzluff, J.M. et al., eds; Springer, 2008).

[11] G.B. Smith, Commentary: Environmental nanophotonics and energy, J Nanophotonics 5 (2011) 1010301 (6pp).

[12] G.B. Smith and C.G. Granqvist, Chapter 7 in "Green Nanotechnology solutions for sustainability and energy in the built environment” (CRC Press, Taylor and Francis, Boca Raton, FL USA , 2010).

[13] A. Hasan, S.J. McCormack, M.J. Huang, B. Norton, Evolution of phase change materials for thermal regulation enhancement of building integrated photovoltaics, Solar Energy 84 (2010) 1601-1612. 
[14] G.B. Smith, A. Gentle, P. Swift and A. Earp, N. Mronga, Coloured paints based on coated flakes of metal as pigment for enhanced solar reflectance and cooler interiors: Description and theory, Solar Energy Mat. and Solar Cells 79 (2003) 163 177.

[15] A. Synnefa, M. Santamouris, K. Apostolakis, On the development, optical properties and thermal performance of cool colored coatings for the urban environment, Solar Energy 81 (2007) 488-497.

[16] G.B. Smith, Amplified radiative cooling via optimised combinations of aperture geometry and spectral emittance profiles of surfaces and the atmosphere, Solar Energy Mat and Solar Cells 93 (2009) 1696-1701.

[17] F. Trombe, Perspectices sur l'utilization des rayonnements solaires et terrestres dans certaines régions du monde, Rev. Gén. Therm. 6 (1967) 1285-1314. [18] EnergyPlus version 6.0.0.023 October 2010 available at http://apps1.eere.energy.gov/buildings/energyplus/ [19] Sydney RMY (Representative Meteorological Year) http://apps1.eere.energy.gov/buildings/energyplus/cfm/weather data3.cfm/regio

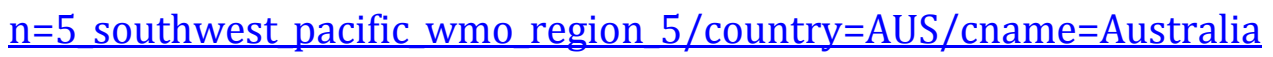


Figure captions

1. Composition of energy flows into and through an insulated roof when no other heating or cooling is present internally, and neglecting water condensation or evaporation from the roof.

2. Schematic of the simple box structure used in modeling. Windows are absent, walls and floor are highly insulated and in base results impervious to airflow. No internal gains are included in base results. Inner dimensions are $10 \times 10 \times 2.4$ in metres. Maximum zone temperature is set at $25^{\circ} \mathrm{C}$.

3. Average monthly and 6 monthly cooling loads, per day for five select parameter combinations chosen to illustrate the weak impact of $\mathrm{R}$ at low $\mathrm{A}_{\text {sol }}$ and the large heat gains arising as $\mathrm{A}_{\text {sol }}$ rises at fixed $\mathrm{R}$.

4. Peak heat gain in $\mathrm{kW}$ per $100 \mathrm{~m}^{2}$ of roof as a function of $U=1 / \mathrm{R}$ for six combinations of $\left(A_{\text {sol }}, E\right)$.

5. Daily average cooling load per $100 \mathrm{~m}^{2}$ over six months as a function of $\mathrm{U}$ $=1 / R$ for six combinations of $\left(A_{\text {sol }}, E\right)$.

6. Cost benefit of peak load reduction expressed as cost per $\mathrm{kW}$ reduction in peak load per $100 \mathrm{~m}^{2}$ of roof for six combinations of $\left(A_{\text {sol }}, E\right)$. Cost is assumed to rise linearly with insulation thickness or R-value and cost scaling is based on $\$ 168.8$ per unit R-value per $100 \mathrm{~m}^{2}$.

7. Cost benefit of average daily load reduction over 6 months expressed as cost per $\mathrm{kWh}$ reduction per day per $100 \mathrm{~m}^{2}$ of roof for six combinations of $\left(\mathrm{A}_{\text {sol }}\right.$, E). Cost scaling assumptions as in figure 6. 


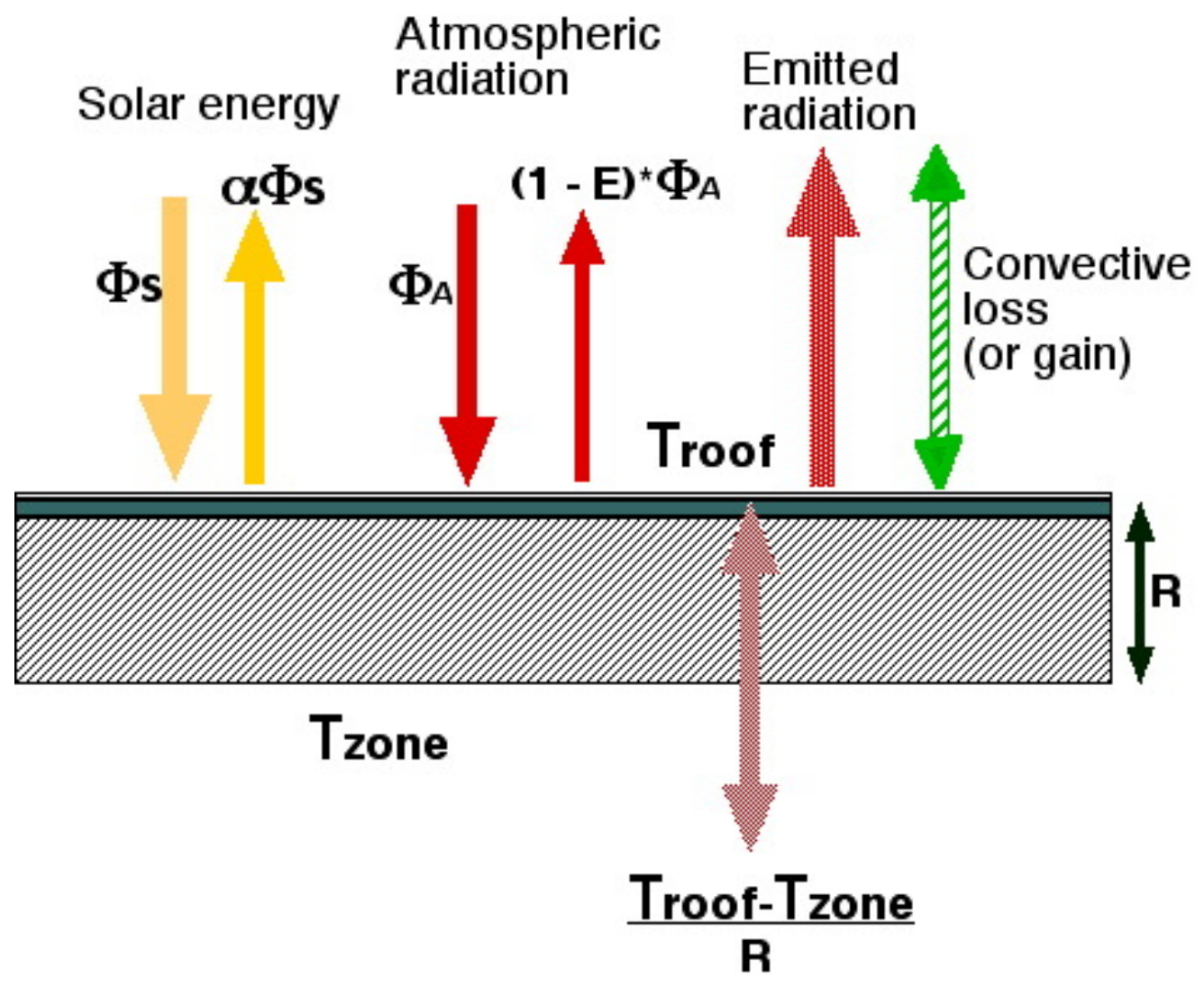

Fig. 1

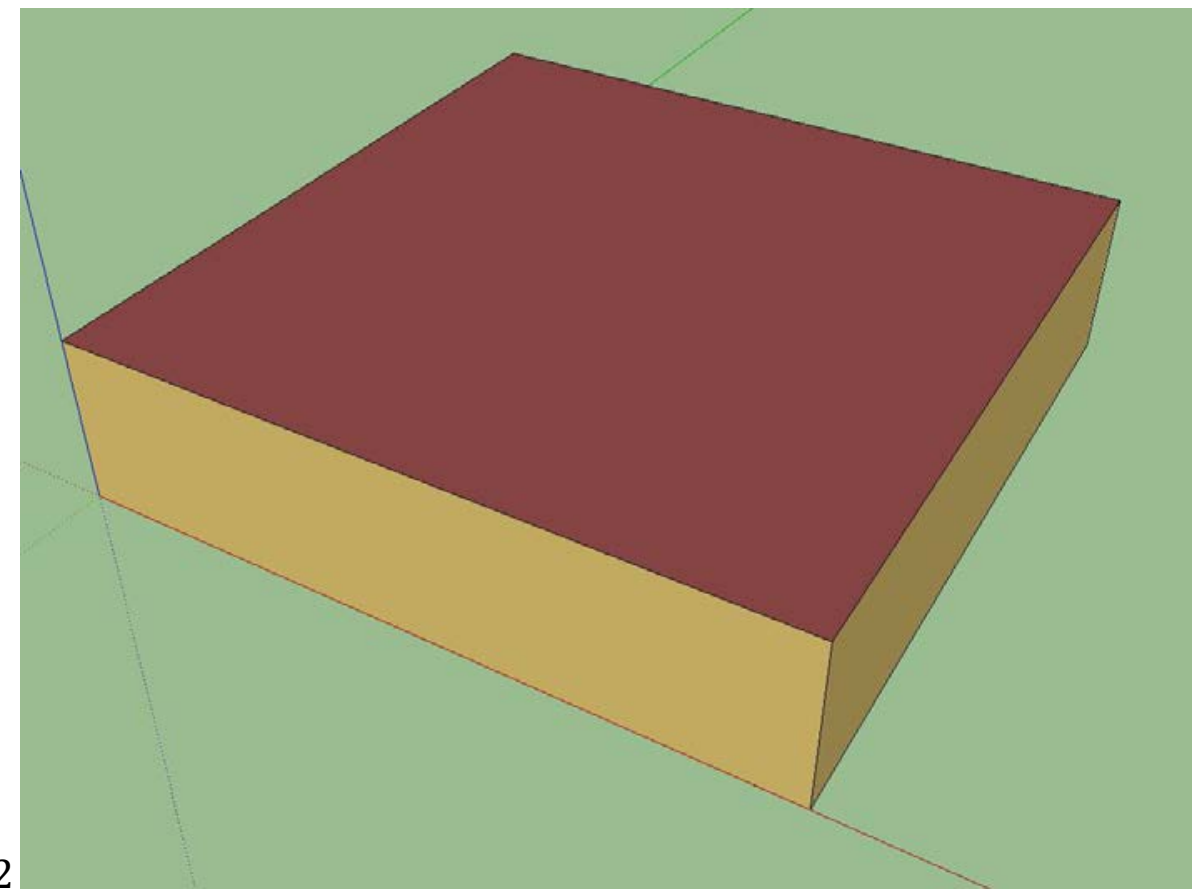

Fig.2 
Fig3.
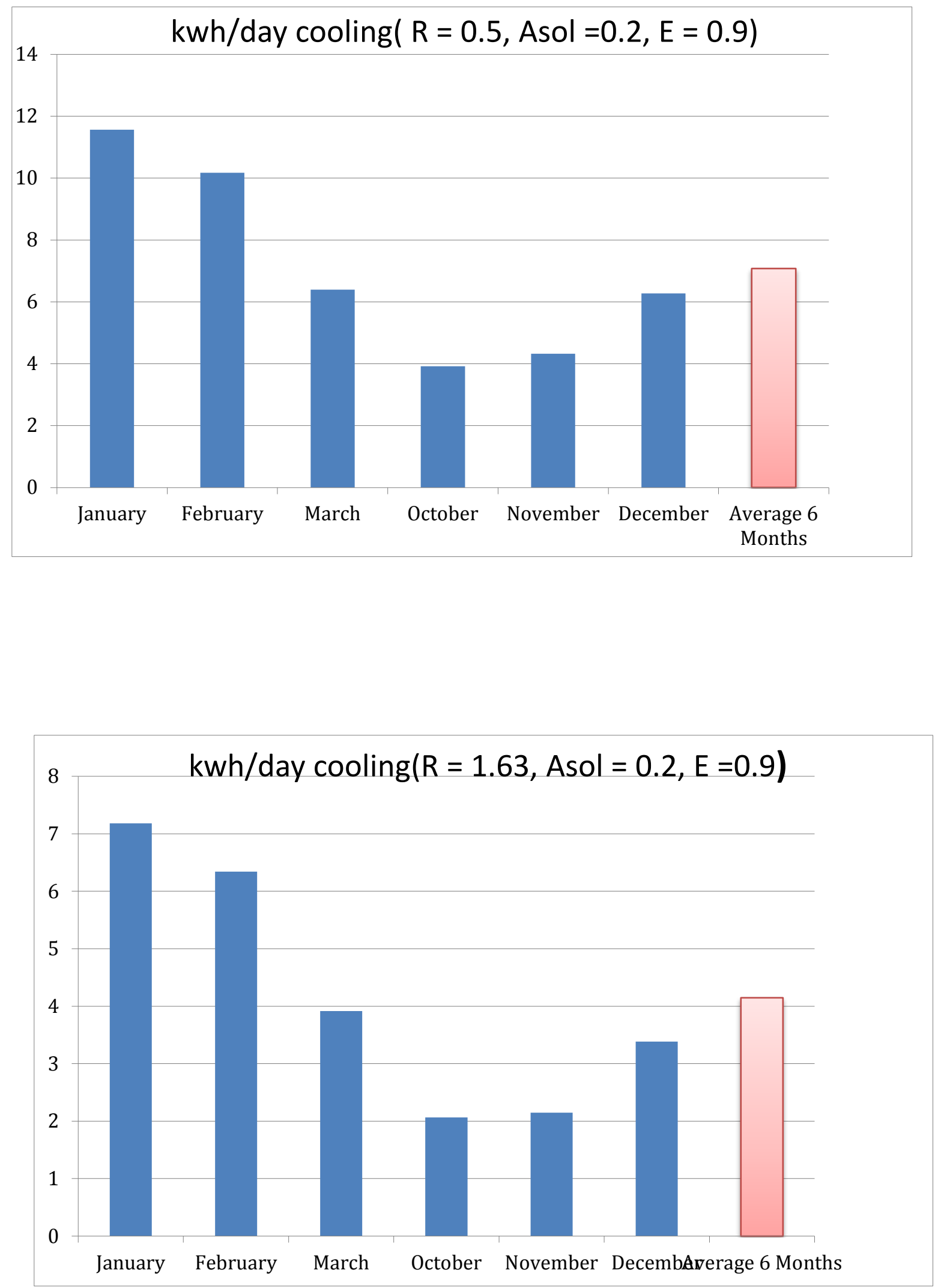

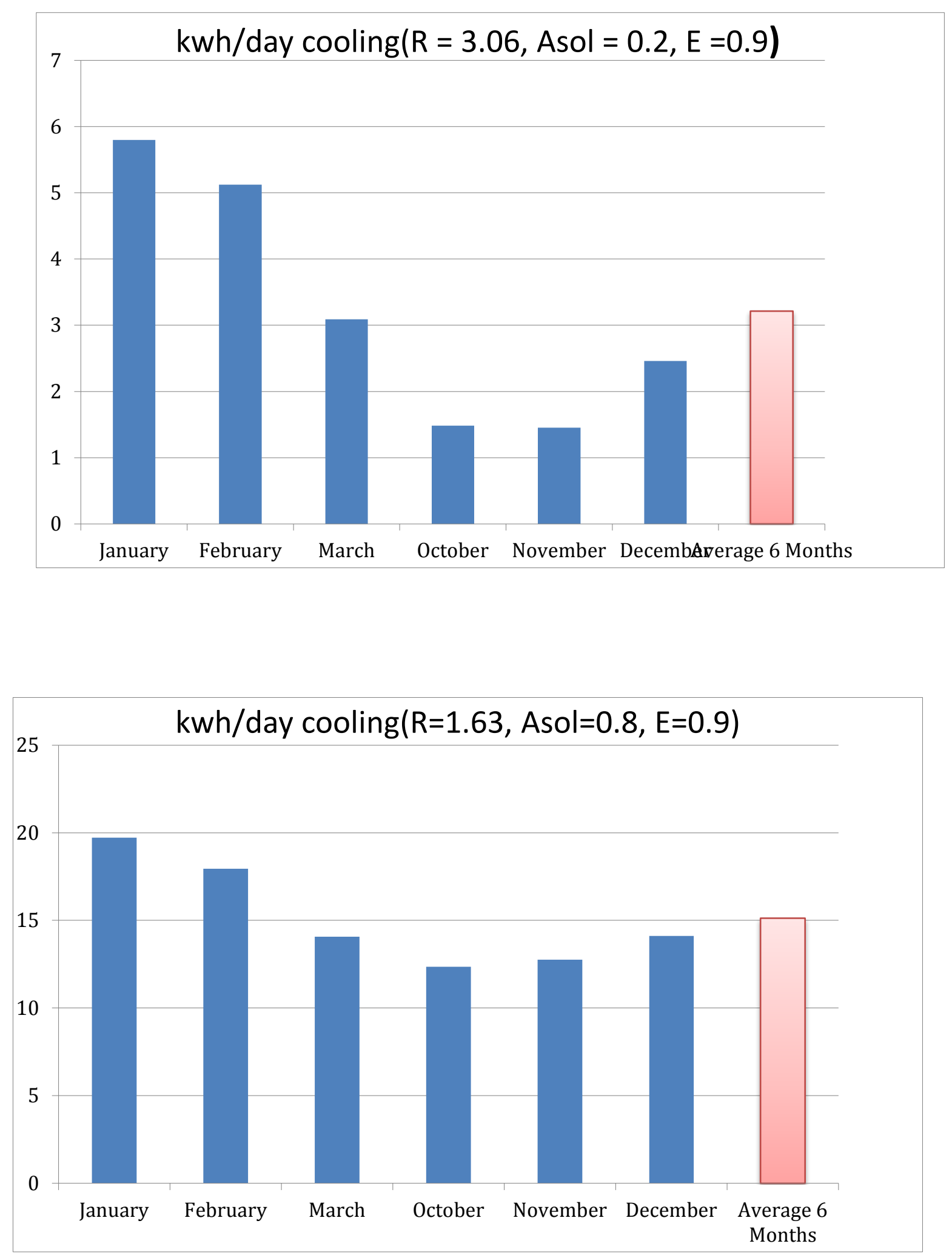


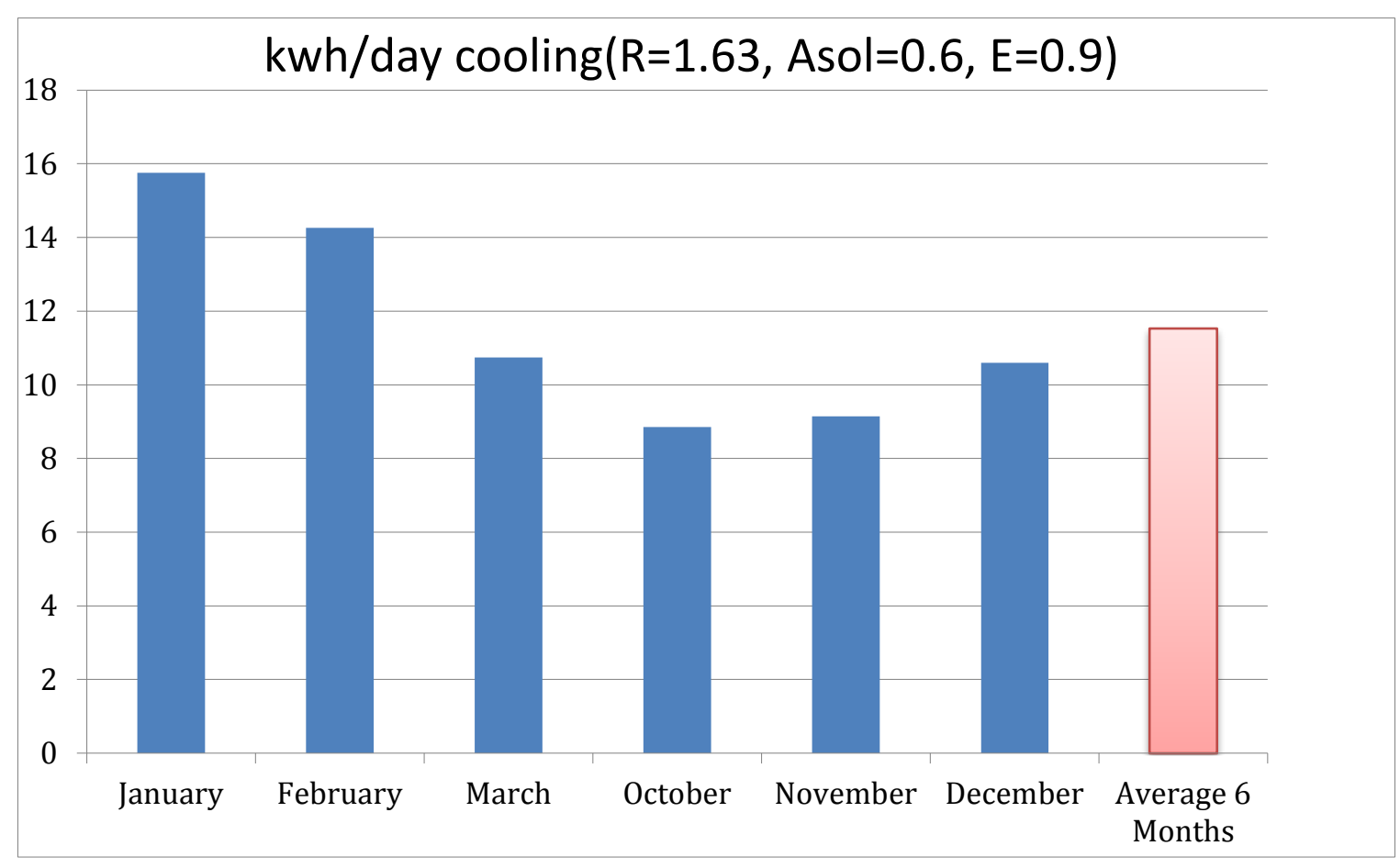


Fig. 4

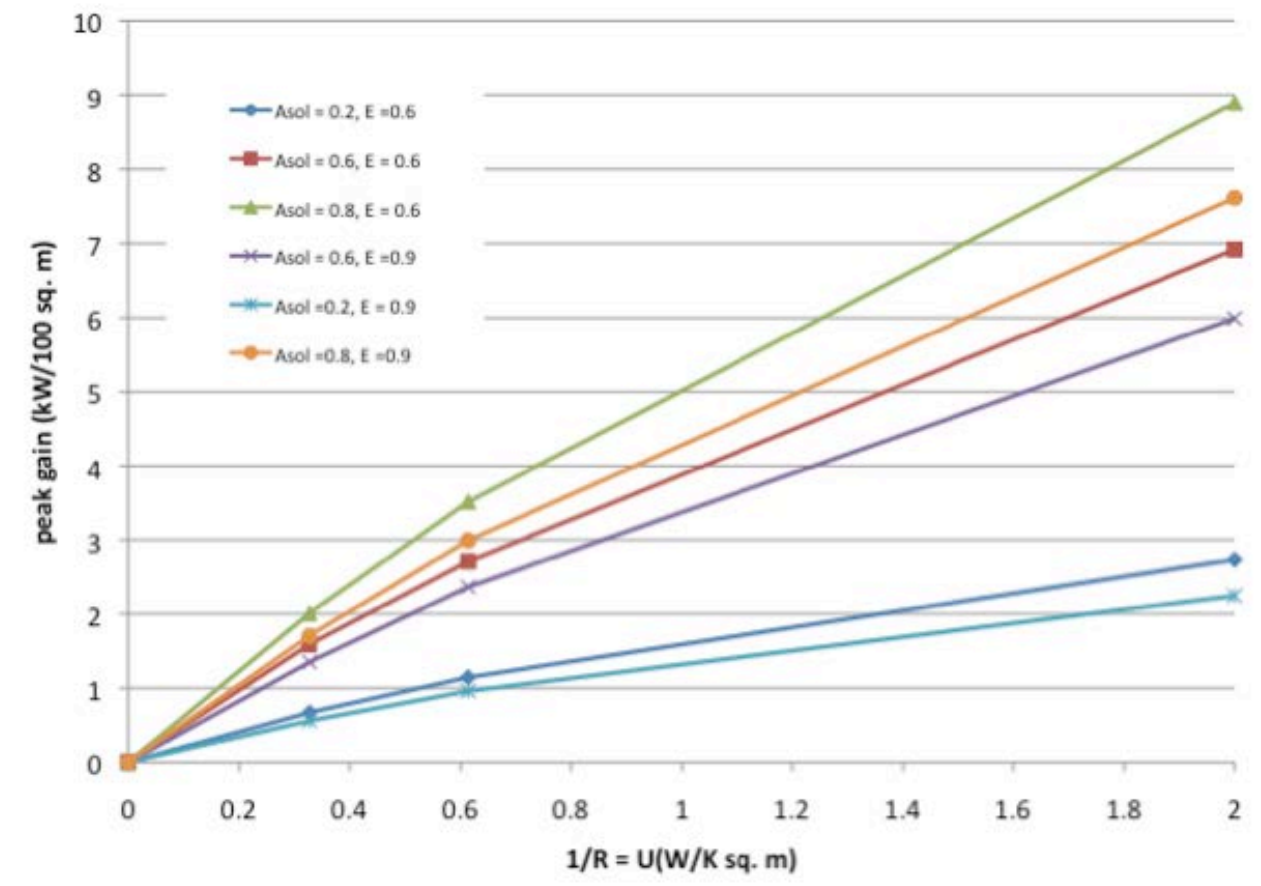




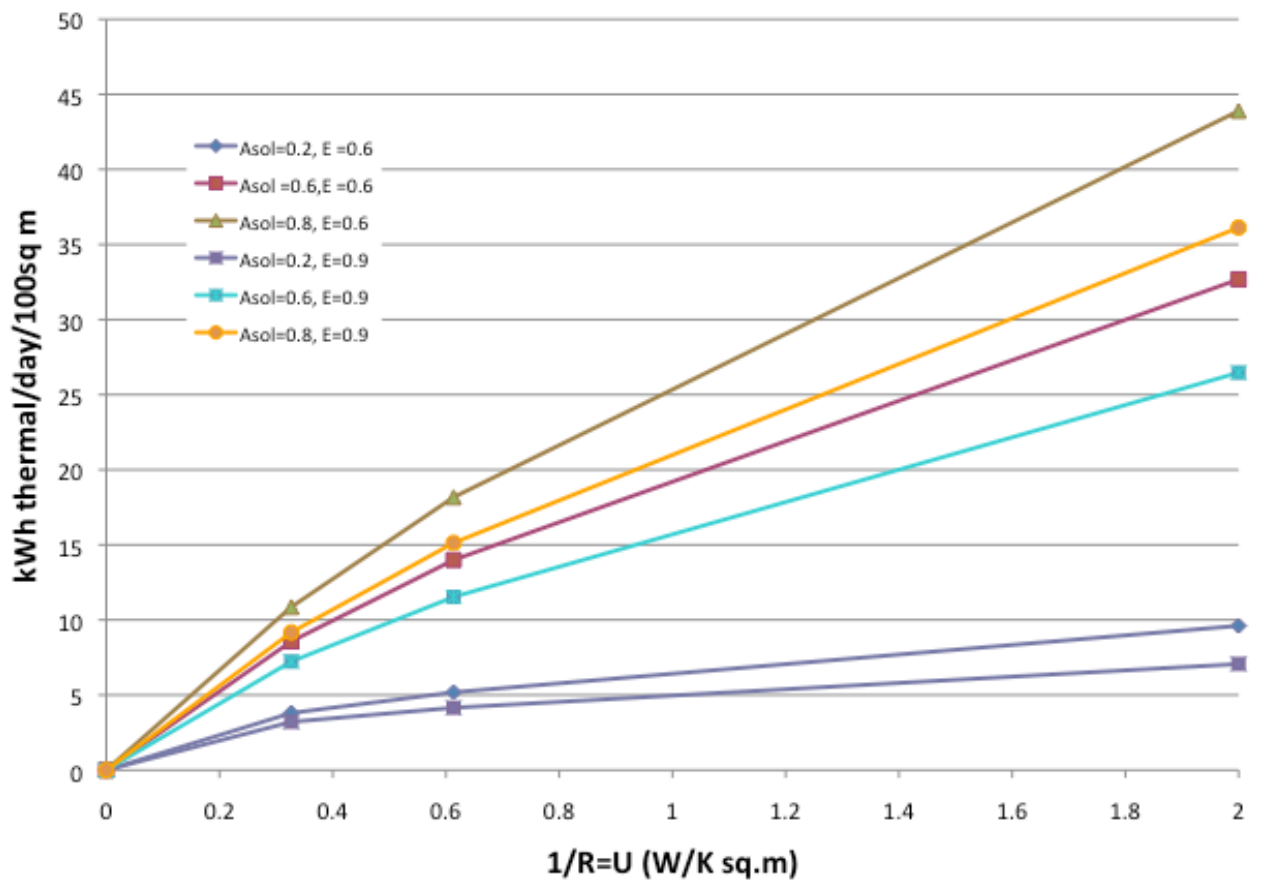

Fig 5

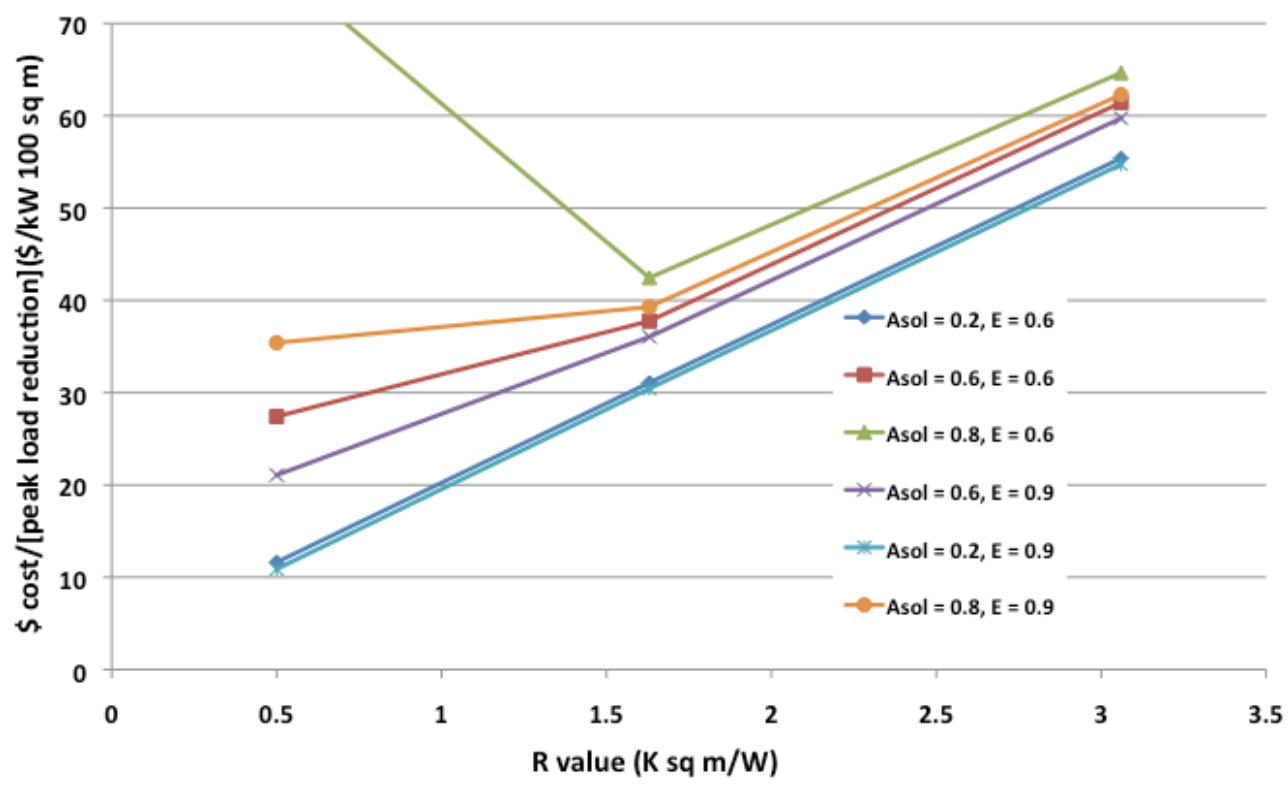

Fig. 6 
Fig. 7

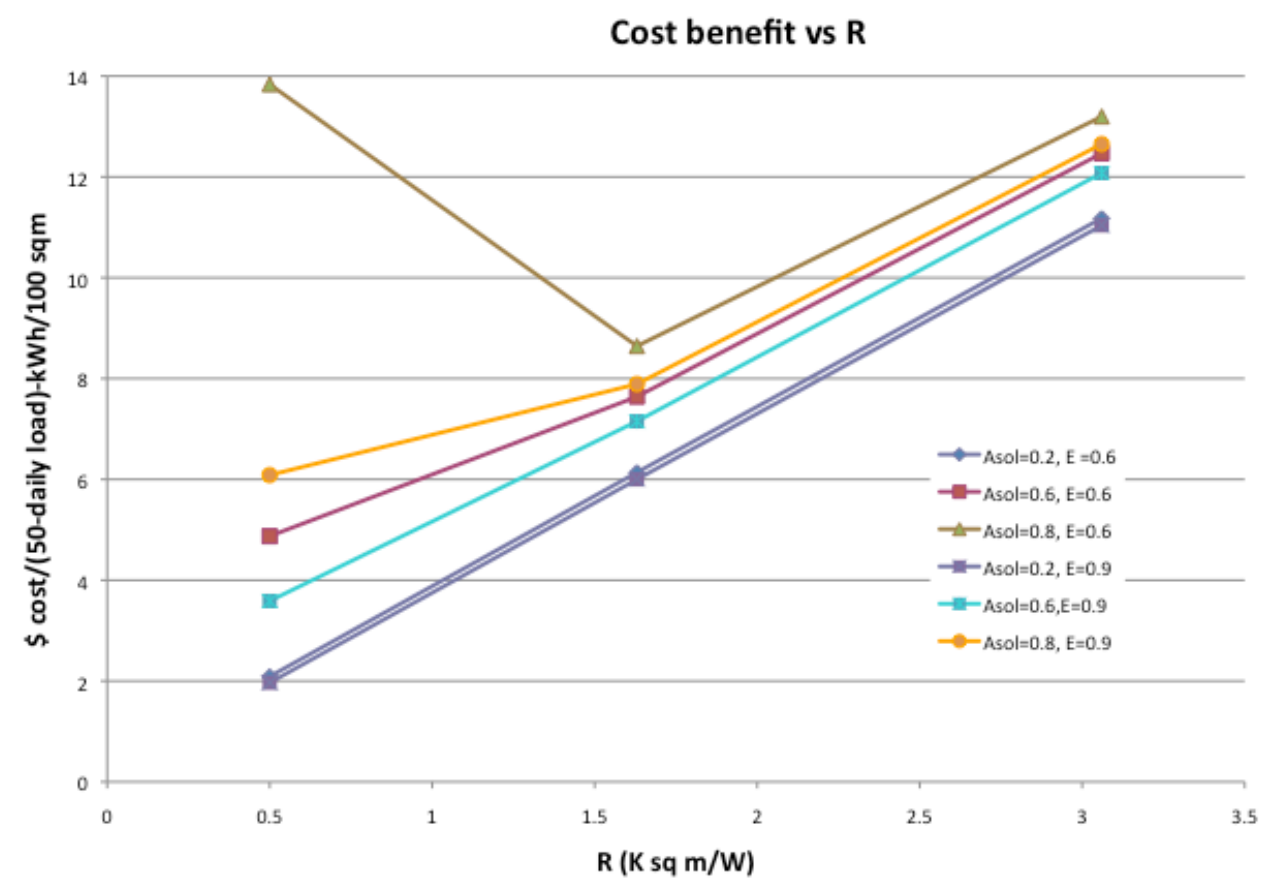

